\title{
Prevalence and modes of complementary and alternative medicine use among peasant farmers with musculoskeletal pain in a rural community in South-Western Nigeria
}

\author{
Chidozie Emmanuel Mbada1*, Tijani Lukman Adeyemi', Rufus Adesoji Adedoyin ${ }^{1}$, Hakeem David Badmus ${ }^{2}$, \\ Taofeek Oluwole Awotidebe ${ }^{1}$, Olujide Olusesan Arije $^{3}$ and Olorunfemi Sunday Omotosho ${ }^{3}$
}

\begin{abstract}
Background: Anecdotally, use of Complementary and Alternative Medicine (CAM) for Musculoskeletal Pain (MSP) is common in Nigeria; however, there seems to be a dearth of empirical data on its prevalence and mode of use. This study investigated the prevalence and modes of use of CAM for MSP among farmers in a rural community in South-western Nigeria.

Methods: This cross-sectional survey employed multistage sampling technique guidelines for conducting community survey by the World Health Organization among rural community farmers in Gudugbu village, Oyo State, Nigeria. A questionnaire developed from previous studies and validated by expert reviews was used to assess prevalence and modes of CAM use. Data was analyzed using descriptive and inferential statistics. Alpha level was set at $p<0.05$.

Results: A total of 230 consenting rural farmers volunteered for this study with a valid response rate of $93.9 \%$ $(n=216)$. The lifetime, 12-month and point prevalence of CAM for MSP was $96.8 \%$ respectively. Herbal therapy and massage were the predominant types of CAM therapies among previous ( 83.8 and $80.1 \%$ ) and current CAM users (37.5 and $37.5 \%$ ). CAM was largely used as sole therapy for MSP (75.5\%) and also in combination with orthodox medicine $(23.6 \%)$, and it is consumed on daily basis (21.8\%). CAM was perceived to be very good in maintaining a healthy life (87.1\%) and has less side effects (74\%) and more healthy than taking doctors' prescriptions (63.4\%).
\end{abstract}

Conclusion: There is a high prevalence of CAM among Nigerian rural farmers. The most commonly employed CAM for MSP were herbal remedies and massage which are attributable to beliefs on their perceived efficacy.

\section{Introduction}

Musculoskeletal Pain (MSP), especially in the chronic stage is a major public health problem [1] and it is associated with limitation in activity of daily living, loss of workplace productivity, high cost of unemployment compensation, disability and high frequency of health seeking [2,3]. Studies suggest that the use of Complementary and Alternative Medicine (CAM) is high and increasing globally [4-7] and chronic MSP is the single most reported reason for use of CAM [6, 7].

\footnotetext{
* Correspondence: doziembada@yahoo.com

'Department of Medical Rehabilitation, College of Health Sciences, Obafemi Awolowo University, lle - Ife, Nigeria

Full list of author information is available at the end of the article
}

CAM definition is inconclusive and varies in different contexts. However, Ernst [8] described CAM as "diagnosis, treatment, and/or prevention which complements mainstream medicine by contributing to a common whole, satisfying a demand not met by orthodoxy, or diversifying the conceptual frameworks of medicine". Independently or in addition to conventional therapy, sufferers of MSP consume a wide range of "natural health products", "herbal remedies" and other supplements or interventions $[6,7$, 9], but, the therapeutic efficacy and side effects of most of these are yet to be sufficiently clarified [10].

Being specific, the National Center for Complementary and Alternative Medicine [11] describes complementary medicine as health care systems, practices, and products 
that are not generally considered part of conventional medicine but are used together with conventional medicine, and alternative medicine is used in place of conventional medicine. As such, CAM covers a heterogeneous spectrum of ancient to new-age approaches that purport to prevent or treat disease [12]. The use of CAM in combination with conventional therapies has a global coverage without particular special bias to either the developed or developing countries. The World Health Organization (WHO) [13] estimates that 70-80\% of patients in the developed countries use at least one form of CAM. Specifically, developed countries such as the United Kingdom [14-16] and the United States of America [17, 18] have empirical reports on high utilization and practice of CAM for MSP. Consequently, there have been advocacies and legislations to situate CAM practice within the National Health Sector in the developed countries [19-22]. Also, some countries like China, Hong Kong, India, Singapore and South Korea have integrative medicine that combines conventional and CAM treatments for which there is evidence of safety and effectiveness and/or dual healthcare delivery system involving both conventional western medicine and CAM [12, 23-29].

Despite, international reports on high preponderance of CAM use for MSP in the developing countries in the range of $20-80 \%$ [30-32], there are still few countryspecific estimates on the prevalence of CAM use for MSP in Africa. Generally, over $80 \%$ of Africa's populations depend on traditional healing modalities including herbal remedies, for health maintenance and therapeutic management of disease [33]. A study showed that about $85 \%$ of Nigerians use CAM for healthcare and psychosocial benefits owing to harrowing poverty and dissatisfaction with conventional medical care [34]. Specifically, CAM, mostly in form of herbal remedies has been used among Nigerian patients with varying conditions such as malaria [35, 36], convulsion and epilepsy [37], various forms of cancer [38], sickle cell anaemia [39] and high blood pressure [32]. Despite reports of some studies on high prevalence of MSP in Nigeria [40-43], there seems to be a dearth of empirical data on the prevalence and modes of use of CAM for MSP in Nigeria. The objective of this study was to assess the prevalence and modes of CAM in the management of MSP among farmers in a rural community in South-western Nigeria.

\section{Materials and Methods}

This study employed the multistage random sampling procedure to select one (i.e. Oyo state) of the six states that made up the South-Western Nigeria. A list of communities in Oyo State that are typically rural based on the Nigerian national statistical offices definition of rural area [44] were purposively enlisted. The peculiar attribute for enlistment of communities included low population densities, small settlement size, low infrastructure development, and lack of access to services. Gudugbu located in Oyo East Local Government was randomly selected from the list of the rural communities. Gudugbu is also a catchment village for the neighboring rural communities and hamlets. Gudugbu houses the only school and health centre in the area. The villagers consist majorly of Oyo speaking Yoruba indigenes and also some non-indigenes as Igbo, Abasa, Egede, and Togolese people. There are twelve hamlets (smaller villages) under the control of the Baale (i.e. the chief) of Gudugbu.

Based on the World Health Organization [45] guideline for conducting community surveys, eight out of the twelve hamlets that made up Gudugbu community were randomly chosen. A hamlet was used as the primary sampling unit and selection was based on simple random sampling with replacement from a bowl containing 12 pieces of coded numbers. In each hamlet, nine houses were selected at random. The first house to be surveyed was randomly chosen, thereafter, every other house was surveyed until the ninth as the houses do not have local government registration numbers. In order to prevent oversourcing each household, a maximum of three consenting adults aged eighteen years and older were recruited from a household. A minimum of 27 respondents were expected from each hamlet. A minimum sample of 216 respondents were expected to be recruited based on the number of households to be sampled. However, 250 individuals were approached for survey in order to accommodate for refusal of participation. Only 230 individuals who met the inclusion criteria of a positive history or present use of CAM to manage a physician or selfdiagnosed MSP responded in this study. The response rate in this study was $92.0 \%$ (i.e.230/250). However, 14 copies of the questionnaire were found not valid for analysis owing to incomplete information. Therefore, the valid response rate in this study was 93.9 \% (i.e. 216/230). All the respondents in this study were peasant farmers.

A structured self-administered questionnaire was developed from previous tools used in similar studies by Ramsey et al. [46], Herman et al. [47] and Patterson and Arthur [48] was used for this study. Items in the prototype questionnaires that were not culturally relevant to the study population were removed or modified. For example, religious traditions such as Judaism, Hinduism, Mormonism etc., Acupuncture, aromatherapy, ayurveda, homeopathy, and Yoga among others that were part of the prototyped tools were not included in this study's instrument because they are not culturally relevant in the study environment. The three section questionnaire used in this study was scrutinized for content validity by expert reviews. The first section of the questionnaire sought information on demographic characteristics of the respondents, the second section obtained information on 
musculoskeletal disorders and CAM use while the last section using a likert scale of 1-5 sought information on beliefs about CAM use among the respondents. The parts of the questionnaire that seeks information about CAM modes and level of involvement with providers and beliefs towards CAM use were adapted from the study by Patterson and Arthur [48]. However, because of the literacy level of the rural population in this study, interviewer-administered questionnaire mode was also employed for volunteers who were not literate in either English or Yoruba (the local dialect in the study environment) language. The interview was carried out by the second author of this article only in order to prevent variation in questionnaire administration and ensure standardization. CAM was defined in this study as a range of health practices involving use of herbal therapy, massage therapy, concoction or black soap bath, body incisions or medicinal scarifications, dietary supplementary diets or fasting, prayer or incantations, mindbody interventions (mind-body interventions in this study was conceived as the use of the mind ability through meditation and prayer, and other inspired channels involving music and dance to alter physical symptoms), heat therapy, bone-setting and spinal manipulation. Ethical approval for this study was obtained from the Ethics and Research Committee of the Institute of Public Health, Obafemi Awolowo University, Ile-Ife, Nigeria.

\section{Statistical analysis}

Data was summarized by using the descriptive statistics of mean, standard deviation, range and percentages. Prevalence of CAM use was estimated as the proportion of the sample population of the eligible respondents with MSP who reported a positive history (lifetime or within the past 12 months) or current use of CAM. Data was completed using Statistical Package for Social Sciences (SPSS) software version 16.0.

\section{Results}

The mean age of the respondents was $41.2 \pm 16$ years. The respondents were mostly married (83.3\%), within the age bracket of 35-44 yrs (26.4\%), of Islamic faith $(77.3 \%)$ and with no formal education (62 \%). The demographic characteristics of the respondents are presented in Table 1. The lifetime, 12-month and current prevalence of CAM for MSP were all $96.8 \%$ respectively. Modes of CAM use within the past 12-month to the study showed that Herbal therapy (83.8 \%) and massage (80.1 \%) were mostly employed for MSP. Similarly, Herbal therapy (37.5\%) and massage (37.5\%) were the most commonly used therapies among current CAM users (Table 2). From this study, $69.9 \%$ of the respondents indicated Islamic religion influenced their predisposition to CAM use while $15.3 \%$ of those of Christian
Table 1 Socio-demographic Characteristics of the Respondents $(\mathrm{N}=216)$

\begin{tabular}{|c|c|c|}
\hline Variable & Frequency & Percentage (\%) \\
\hline \multicolumn{3}{|l|}{$\overline{\text { Age }}$} \\
\hline$<25 \mathrm{yrs}$ & 38 & 17.6 \\
\hline $25-34$ yrs & 36 & 16.7 \\
\hline $35-44$ yrs & 57 & 26.4 \\
\hline $45-54$ yrs & 38 & 17.6 \\
\hline $55-64$ yrs & 18 & 8.3 \\
\hline$>65$ yrs & 29 & 13.4 \\
\hline \multicolumn{3}{|l|}{ Sex } \\
\hline Male & 108 & 50.0 \\
\hline Female & 108 & 50.0 \\
\hline \multicolumn{3}{|l|}{ Marital Status } \\
\hline Single & 34 & 15.7 \\
\hline Married & 180 & 83.3 \\
\hline Separated & 2 & 0.9 \\
\hline \multicolumn{3}{|l|}{ Religion } \\
\hline Islam & 167 & 77.3 \\
\hline Christianity & 41 & 19.0 \\
\hline Others & 8 & 3.7 \\
\hline \multicolumn{3}{|c|}{ Educational qualification } \\
\hline Primary & 42 & 19.4 \\
\hline Secondary & 38 & 17.6 \\
\hline Tertiary & 2 & 0.9 \\
\hline None & 134 & 62.0 \\
\hline \multicolumn{3}{|l|}{ Ethnicity } \\
\hline Yoruba & 166 & 76.9 \\
\hline Igbo & 5 & 2.3 \\
\hline Togolese & 15 & 6.9 \\
\hline Others & 30 & 13.9 \\
\hline \multicolumn{3}{|l|}{ Monthly Income } \\
\hline$<N 7500$ & 171 & 79.2 \\
\hline N7500-N15000 & 34 & 15.7 \\
\hline N15000-N50000 & 11 & 5.1 \\
\hline
\end{tabular}

$N$ Naira. N165.50 at the time of the study was equivalent to $\$ 1$

belief reported that their religion influence their use of CAM for MSP.

Table 3 shows the health care practices and the use of CAM for musculoskeletal pain among the respondents. A majority $(75.5 \%)$ of the respondents used CAM exclusively for MSP, while $23.6 \%$ used CAM in addition to orthodox medicine. CAM for MSP was used on daily (21.8\%), weekly (13.9\%), monthly (5.6\%) and annual (3.2\%) basis by the respondents. A majority of the respondents believed that CAM is very good in maintaining a healthy life $(87.1 \%)$ and has less side effects (74 \%). $63.4 \%$ of the respondents believed that CAM 
Table 2 Lifetime, 12-month and point prevalence and pattern of Complementary and Alternative Medicine (CAM) use for musculoskeletal pain $(\mathrm{N}=216)$

\begin{tabular}{|c|c|c|}
\hline Variable & Frequency & Percentage (\%) \\
\hline \multicolumn{3}{|l|}{ Lifetime Prevalence of CAM use } \\
\hline Yes & 209 & 96.8 \\
\hline No & 7 & 3.2 \\
\hline \multicolumn{3}{|l|}{ 12-month Prevalence of CAM use } \\
\hline Yes & 209 & 96.8 \\
\hline No & 7 & 3.2 \\
\hline \multicolumn{3}{|l|}{ Point/Current Prevalence of CAM use } \\
\hline Yes & 209 & 96.8 \\
\hline No & 7 & 3.2 \\
\hline \multicolumn{3}{|l|}{$\begin{array}{l}\text { Pattern of within 12-month previous use of } \\
\text { CAM }\end{array}$} \\
\hline Herbal therapy & 181 & 83.8 \\
\hline Massage & 173 & 80.1 \\
\hline Concoction and black soap bath & 130 & 60.2 \\
\hline Body incisions or medicinal scarifications & 24 & 11.1 \\
\hline Dietary supplementary diets or fasting & 2 & 1.0 \\
\hline Prayer or incantations & 14 & 6.5 \\
\hline Heat therapy & 16 & 7.4 \\
\hline Mind-body intervention & 33 & 15.3 \\
\hline Others & 3 & 1.5 \\
\hline \multicolumn{3}{|l|}{ Pattern of Current use of CAM } \\
\hline Herbal therapy & 81 & 37.5 \\
\hline Massage & 81 & 37.5 \\
\hline Concoction and black soap bath & 36 & 16.7 \\
\hline Body incisions or medicinal scarifications & 13 & 6 \\
\hline Prayers & 6 & 2.8 \\
\hline Heat therapy & 14 & 6.5 \\
\hline Mind-body intervention & 71 & 32.8 \\
\hline Others & 24 & 11.1 \\
\hline
\end{tabular}

involves natural plant formulas which are more healthy than taking drugs given by the medical doctors. $87 \%$ of the respondents believed that more people would likely use CAM if the government will develop them and open CAM clinics. $63.7 \%$ of the respondents believed that CAM is more effective in healing than orthodox medicine. $44.5 \%$ of the respondents disagreed with the opinion that people who do not have money for treatment from medical doctors are more likely to use CAM. The respondents' belief about the use of CAM for MSP is presented in Table 4.

\section{Discussion}

This present study found a high prevalence of $96.8 \%$ on the use of CAM for MSP among Nigerian rural farmers.
Table 3 Complementary and alternative treatment of musculoskeletal pain $(\mathrm{N}=216)$

\begin{tabular}{lll}
\hline Variable & Frequency & Percentage (\%) \\
\hline Pattern of CAM use & 163 & 75.5 \\
CAM only & 51 & 23.6 \\
CAM with Orthodox medicine & 214 & 99.1 \\
Total & 2 & 0.9 \\
Missing system & & \\
Frequency of use of CAM & 36 & 16.7 \\
None & 81 & 37.5 \\
Anytime with pain & 47 & 21.8 \\
Daily & 30 & 13.9 \\
Weekly & 12 & 5.6 \\
Monthly & 7 & 3.2 \\
Annually & 3 & 1.4 \\
Less than once a year & 216 & 100.0 \\
Total & & \\
Frequency of visits to CAM Practitioners & & 62.0 \\
None & 134 & 20.4 \\
Anytime there is pain & 44 & 5.6 \\
Daily & 12 & 4.6 \\
Weekly & 10 & 100.0 \\
Monthly & 13 & \\
Others & 3 & \\
Total & 216 & \\
\hline & & \\
\hline
\end{tabular}

This finding is consistent with literature reports on high and increasing use of CAM for MSP worldwide $[6,7]$. Epidemiological data indicate that about 28 to $90 \%$ of people with musculoskeletal disorders such as arthritis use CAM [49-53]. Some country-specific details reveal that about $20 \%$ of patients in the Netherlands [54], $32.3 \%$ in South Korea [55], 49 \% in France [54] and as many as $82 \%$ in the United State [56] use CAM for conditions such as musculoskeletal disorders. A WHO reports also submit that 70-80 \% of patients in developed countries use at least one form of CAM [57].

From this study, $23.6 \%$ of the rural farmers reported use of CAM in combination with conventional medicine. This finding buttresses a report that combination of CAM with conventional therapies is most commonly used in MSP [58]. Survey reports from the United Kingdom found that between 39 and $83 \%$ of patients consulting general practitioners were active in the use of CAM $[15,59,60]$. A Croatia study by Čižmešija et al. [61] found a prevalence rate of $53.5 \%$ while a survey in the USA, found that $21 \%$ of patients visiting with their primary care physicians, had used CAM treatment for the medical condition associated with that physician visit [62]. However, there is a paucity of exclusive studies on use of CAM for MSP among 
Table 4 Belief about Complementary and Alternative Medicine (CAM) ( $N=216)$

\begin{tabular}{|c|c|c|c|}
\hline & Agree & Undecided & Disagree \\
\hline Item & n (\%) & n (\%) & n (\%) \\
\hline 1. CAM is very good in maintaining a healthy life & $188(87.1)$ & $23(10.6)$ & $5(2.3)$ \\
\hline 2. There are less side effects when taking CAM therapies & $160(74.1)$ & $33(15.3)$ & $21(9.7)$ \\
\hline 3. CAM are healthier than taking conventional drugs & $137(63.4)$ & $42(19.4)$ & $37(17.1)$ \\
\hline 4. CAM use will increase if the government will develop it & $188(87.0)$ & $23(10.7)$ & $5(2.3)$ \\
\hline 5. CAM enhances the body's own defense mechanism and promotes self-healing & $183(84.8)$ & $26(12.0)$ & $7(3.2)$ \\
\hline 6. The more knowledge about CAM, the more the use & $190(88.0)$ & $23(10.6)$ & $3(1.4)$ \\
\hline 7. Parents should teach their children about CAM & $192(88.9)$ & $21(9.7)$ & $3(1.4)$ \\
\hline 8. The more the friends that use CAM the more likely to use CAM & $180(83.3)$ & $22(10.2)$ & $14(6.5)$ \\
\hline 9. CAM is more effective than orthodox medicine & $142(65.7)$ & $37(17.1)$ & $7(3.2)$ \\
\hline 10. CAM is good for the physical, mental and spiritual health & $6(2.8)$ & $177(81.9)$ & $33(15.3)$ \\
\hline 11. The more the fears for conventional medicine, the more likely to use CAM & $104(48.2)$ & $28(13.0)$ & $84(38.9)$ \\
\hline 12. People who do not have money are likely to use CAM & $86(39.8)$ & $34(15.7)$ & $96(44.4)$ \\
\hline
\end{tabular}

farmers. Nonetheless, a study on use of CAM among patients with chronic diseases in Croatia found a prevalence of $54.8 \%$ among farmers [63]. Cuelar [64] stated that people in rural areas experience a variety of unmet medical needs probably as a result of limited access to primary care, fewer resources to choose from, lower income, less comprehensive healthcare system, lower level of formal education and geographic isolation. In like manner, this present study setting and people seem to be share similar characteristics with the above description. It is adduced that the above stated factors may have contributed to the high prevalence of CAM use for MSP in this study.

This study found that herbal therapy and massage were the most often employed CAM for MSP. This study correlates with some previous findings that reported that use of herbal remedies is relatively common in most developing countries with a prevalence of $20-80 \%$ [30-32]. According to Singh et al. [31], the most commonly used form of CAM in Nigeria is herbal preparations. Also, Bernard et al. [65] reported that Hispanic and African American adults with arthritis were more likely to take herbs orally, or use ointments and were less likely to see a physician for arthritis than were non-Hispanic whites. Rural dwelling individuals may feel the need to use herbal therapy and massage due to the perceived efficacy of these interventions based on folklore or family traditions and the availability of these practices.

From this study, about $70 \%$ of the farmers indicated that their CAM use decisions were influenced by Islamic religion. Religion plays an important role in the choice of health approaches. However, this study did not set out to investigate the role of religion on CAM use. The high number of respondents indicating that Islam influence their decision for use of CAM for MSP may just be as a result of high number of Muslims in the study.
Furthermore, this study also revealed a wide range of CAM practices. Exclusive and inclusive use of CAM for MSP was common among Nigerian rural farmers. However, the higher rate of exclusive use of CAM than in combination with conventional therapy in this study may be due to beliefs that CAM alone may sufficiently treat all MSP. According to Bukovcan [66], the most frequently mentioned reason for the use of CAM is the need of a specific therapy who will help them solve the problem which conventional medicine has not recognized or has not found a solution for. This study also shows that a majority of the farmers believed that CAM is very good in maintaining a healthy life and that there were fewer side effects to CAM use for MSP. The farmers believed that CAM are derived from natural plant and are healthier than taking conventional drugs given by a medical doctor, and that CAM is more effective in healing. The farmers also believed that more people would likely use CAM if the government will develop them and open CAM clinics. The beliefs expressed above may be attributable to the users' perceived efficacy of the CAM. These beliefs and speculations are consistent with previous reports on reasons for CAM use in other populations [67-69].

The finding of this study on CAM use for MSP among rural dwellers is an empirical submission of a common anecdote in a previously unexplored African setting. Therefore, physicians, physiotherapists and other health care professionals involved in the management of MSP should come to term with the realities of high and increasing use of CAM for MSP among rural dwellers in Nigeria. Instead of dissuading sufferers of MSP from using CAM as commonly practiced by health care professionals, and also the frequent denials of CAM use by patients seeking conventional medicine, it is recommended 
that health care professionals should enquires about CAM use on a habitual basis. This may help to circumvent and minimize the risks of potential interactions of therapeutic interventions with harmful natural pharmaceutical substance, as well as advance physician-patient relationship and the possibility of formal integration of CAM into conventional practice. Also, the high prevalence and wide range of perceived benefits of CAM use stresses the need for more research into benefits and dangers of herbal remedies and other supplements in Nigeria.

This study was carried out exclusively among rural farmers; therefore, its finding cannot be generalized to other populations and settings in Nigeria. Furthermore, this study assessed the lifetime, 12 months period and point prevalence and modes of CAM use for MSP which could also lead to possible misclassification due to recall bias that is typical of all cross-sectional or self-report studies. It is also possible that some of the respondents in our study may have other pain but perceived as MSP. In addition, a cross-sectional design as employed in this study may not be sufficient to provide evidence on the option of pattern of use of CAM as exclusive or combined with conventional treatments offered by physicians. However, a scaling up of this study on a nationwide platform in the general population and in specific disease conditions is warranted in order to provide a more representative data for policy formulation on CAM use for MSP in Nigeria.

\section{Conclusion}

It was found that the prevalence of CAM use for MSP among Nigerian rural farmers was high with herbal remedies and massage as the most frequently employed therapies. Therefore, health care providers in Nigeria must acknowledge the high use of CAM for MSP among rural farmers and this may influence how health care is administered. Furthermore, these findings may assist to close the gap on the dearth of empirical information on CAM use among rural farmers in Nigerian.

\section{Conflict of interests}

We declare no conflict of interests.

\section{Authors' contributions}

CEM conceived the idea of this study, participated in study's design, data collection and analysis. He prepared the final manuscript for publication. TLA participated in study's design and data collection and drafted the manuscript. RAA, HDB, OOA, and OSO participated in study's design, interpretation of data and drafted the manuscript. All authors read and approved the final manuscript.

\section{Acknowledgements}

The authors wish to thank the African Population and Health Research Centre (APHRC), Nairobi, Kenya for providing technical support through the African Doctoral Dissertation Research Fellowship (ADDRF) Post-Doctoral Fellowship. ADDRF Post-Doctoral Fellowship is funded by the International Development and Research Centre (IDRC), Canada. We gratefully acknowledge the Baale of Gudugbu and the entire community for their permission and co-operation during the survey.

\section{Author details}

'Department of Medical Rehabilitation, College of Health Sciences, Obafemi Awolowo University, Ile - Ife, Nigeria. ${ }^{2}$ Department of Orthopaedic Surgery and Traumatology, Obafemi Awolowo University Teaching Hospitals Complex, Ile - Ife, Nigeria. ${ }^{3}$ Department of Community Health, Obafemi Awolowo University Teaching Hospitals Complex, lle - Ife, Nigeria.

Received: 19 September 2014 Accepted: 27 May 2015

Published online: 06 June 2015

\section{References}

1. Bergman S, Herrström P, Högström K, Petersson IF, Svensson B, Jacobsson LT. Chronic musculoskeletal pain, prevalence rates, and socio-demographic associations in a Swedish population study. J Rheumatol. 2001;28(6):1369-77.

2. Stewart WF, Ricci JA, Chee E, Morganstein D, Lipton R. Lost productive time and cost due to common pain conditions in the UW workforce. JAMA. 2003;290:2443-54.

3. Bedson J, Mottram S, Thomas E, Peat G. Knee pain and osteoarthritis in the general population: what influences patients to consult? Fam Pract. 2007;24:443-53.

4. Wootton JC, Sparber A. Surveys of complementary and alternative medicine: part I. General trends and demographic groups. J Altern Complement Med. 2001;7:195-208.

5. Astin JA. Why patients use alternative medicine: results of a national study. JAMA. 1998;279(19):1548-53.

6. Artus M, Croft P, Lewis M. The use of CAM and conventional treatments among primary care consulters with chronic musculoskeletal pain. BMC Fam Pract. 2007;8:26. doi:10.1186/1471-2296-8-26.

7. Grazio S, Balen D. Complementary and alternative treatment of musculoskeletal pain. Acta Clin Croat. 2011;50(4):513-30.

8. Ernst E, Resch KL, Mills S, Hill R, Mitchell A, Willoghby A, et al. Complementary medicine: a definition. Br J Gen Pract. 1995;45:506.

9. Olatunde S, Boon H, Hirschkorn K, Welsh S, Bajcar J. Roles and responsibilities of pharmacists with respect to natural health products: key informant interviews. Res Social Adm Pharm. 2010;6(1):63-9.

10. Tilburt JC, Kaptchuk TJ. Herbal medicine research and global health: an ethical analysis. Bull World Health Organ. 2008;86(8):577-656.

11. NCCIH's current strategic plan, Exploring the Science of Complementary and Alternative Medicine 2011. Third Strategic Plan 2011-2015, https://nccih.nih.gov/about/plans. Accessed 19/03/2015.

12. Barnes PM, Bloom B, Nahin RL. Complementary and Alternative Medicine Use Among Adults and Children: United States, 2007. National Health Statistics Report. US Department of Health and Human Services. Center for Disease Control and Prevention. 2008; Number 12. Pp 1-24. https://nccih.nih.gov/. Accessed 19/03/2015.

13. World Health Organization. Traditional medicine. 2008. WHO Fact Sheet No. 134 http://www.who.int/topics/traditional_medicine/en/.Accessed 12/04/2014

14. Emslie M, Campbell M, Walker K. Complementary therapies in a local healthcare setting. Part 1: Is there real public demand? Complement Ther Med. 1996:4:39-42.

15. Thomas KJ, Coleman P, Nicholl JP. Trends in access to complementary or alternative medicines via primary care in England: 1995-2001 Results from a follow-up national survey. Fam Pract. 2003;20:575-7.

16. Thomas KJ, Nicholl JP, Coleman P. Use and expenditure on complementary medicine in England: a population based survey. Complement Ther Med. 2001;9:2-11.

17. Eisenberg DM, Kessler RC, Foster C, Norlock FE, Calkins DR, Delbanco TL. Unconventional medicine in the United States. Prevalence, costs and patterns of use. N Engl J Med. 1993;328:246-52.

18. Eisenberger NI, Lieberman M. Why it hurts to be left out: The neurocognitive overlap between physical and social pain. In: Williams KD, editor. The social outcast: ostracism, social exclusion, rejection, \& bullying (Sydney symposium of social psychology). East Sussex: Psychology Press; 2005. p. 210. ISBN 1-84169-424-X.

19. Pinchuck T, Clark R. Medicine for beginners. London: Writers and Readers Publishing Cooperative Ltd.; 1984.

20. Reilly D. Complementary and Alternative medicine in Europe: reflections and trends, The International Symposium Commemorating the 10th Anniversary of Asan Medical Center. 1999. p. 61-71. 
21. Molassiotis A, Fernadez-Ortega P, Pud D, Ozden G, Scott JA, Panteli V, et al. Use of complementary and alternative medicine in cancer patients: a European survey. Ann Oncol. 2005;16(4):655-63.

22. National Center for Complementary and Alternative Medicine. National Institutes of Health. www.nih.gov/about/almanac/organization/NCCAM.htm. Accessed 12/08/2014.

23. Cha YS. Status of health care system related to complementary medicine. Res Inst Healthcare Pol Korean Med Assoc. 2007;5:51-7.

24. Yoon BB. Understanding and misconceptions about complementary medicine: it would be safe under the supervision and command of doctor. Res Inst Healthcare Pol Korean Med Assoc. 2007;5:29-33.

25. Park JS, Shin BC, Kim CB, et al. A policy proposal for the Korean collaboration of Eastern and Western medicine according to a model of the Chinese integrative medicine. J Res Inst Korean Med Daejeon Univ. 2010;19(1):1-7.

26. Chung VC, Ma PH, Lau CH, Griffiths SM. Developing policy for integrating biomedicine and traditional Chinese medical practice using focus groups and the Delphi technique. Evid Based Complement Alternat Med. 2012;11:149512.

27. Ryu JS, Choi BH, Lim BM, Kim SK, Yun YJ. Medical practices and attitudes of dual-licensed medical doctors in Korea. Evid Based Complement Alternat Med. 2013;7:183643.

28. Shirwaikar A, Govindarajan R, Rawat AKS. Integrating complementary and alternative medicine with primary health care. Evid Based Complement Alternat Med. 2013;3:948308.

29. Wang B-R, Choi IY, Kim K-J, Kwon YD. Use of traditional Korean medicine by patients with musculoskeletal disorders. PLoS One. 2013;8(5):e63209.

30. Michie CA. The use of herbal remedies in Jamaica. Ann Trop Paediat. 1992;12:31-6.

31. Singh V, Raidoo DM, Harris CS. The prevalence, pattern of usage and people's attitude towards complementary and alternative medicine (CAM) among the Indian community in Chatsworth. South Africa BMC Complement Altern Med. 2004;4:3. doi:10.1186/1472-6882 -4-3.

32. Amira CO, Okubadejo NU. Frequency of complementary and alternative medicine utilization in hypertensive patients attending an urban tertiary care centre in Nigeria. BMC Complement Altern Med. 2007;7:30. doi:10.1186/1472-6882-7-30.

33. Cizmesija T, Bergman-Markovac B. Use of complementary and alternative medicine among patients in primary health care. Acta Med Croatica. 2008;62:15.

34. Adesina SK. Traditional medical care in Nigeria. http://www.onlinenigeria.com/ links/LinksReadPrint.asp?blurb=574. Accessed 14/04/2014

35. Ajaiyeoba EO, Falade CO, Fawole Ol, Akinboye DO, Gbotosho GO, Bolaji OM, et al. Efficacy of herbal remedies used by herbalists in Oyo State Nigeria for treatment of Plasmodium falciparum infections - a survey and an observation. Afr J Med Med Sci. 2004;33(2):115-9.

36. Okeke TA, Okafor HU, Uzochukwu BS. Traditional healers in Nigeria: perception of cause, treatment and referral practices of severe malaria. J Bio Soc Sci. 2006:38:491-500

37. Danesi MA, Adetunji JB. Use of alternative medicine by patients with epilepsy: a survey of 265 epileptic patients in a developing country. Epilepsia. 1994;35:344-51.

38. Onyiapat JE, Okoronkwo IL, Ogbonnaya NP. Complementary and alternative medicine use among adults in Enugu. Nigeria BMC Complement Altern Med. 2011;11:19. doi:10.1186/1472-6882-11-19.

39. Akinsulie AO, Temiye EO, Akanmu AS, Lesi FE, Whyte CO. Clinical evaluation of extract of Cajanuscajan (Ciklavit) in sickle cell anaemia. J Trop Pediatr. 2005:51:200-5

40. Omokhodion FO. Low back pain in a rural community in South West Nigeria. West Afr J Med. 2002;21(2):87-90.

41. Fabunmi AA, Aba SO, Odunaiya NA. Prevalence of low back pain among peasant farmers in a rural community in South West Nigeria. Afr J Med Med Sci. 2005;34:259-62.

42. Akinpelu AO, Odole A, Odejide AS. Prevalence and Pattern of Musculoskeletal Pain in a Rural Community in Southwestern Nigeria. The Internet Journal of Epidemiology. 2009: 8(2) https://ispub.com/IJE/8/2/5433.

43. Birabi BN, Dienye PO, Ndukwu PO. Prevalence of low back pain among peasant farmers in a rural community in South-South Nigeria. Rural Remote Health. 2012;12:1920

44. National Bureau of Statistics. Social Statistics in Nigeria. Abuja: The NBS Publication, 2009. www.nigerianstat.gov.ng. Accessed 18/08/2014
45. World Health Organization. Guidelines for conducting community surveys on injuries and violence. Edited by Sethi D, Habibula S, McGee K, Peden M, Bennet S, Hyder AA, Klevens J, Odero W, Suriyawongpaisal P. World Health Organization, Geneva. 2004 http://whqlibdoc.who.int/publications/2004/ 9241546484.pdf.

46. Ramsey SD, Spencer AC, Topolski TD, Belza B, Patrick DL. Use of alternative therapies by older adults with osteoarthritis. Arthritis Rheum. 2001;45(3):222-7.

47. Herman CJ, Allen P, Hunt WC, Prasad A, Brady TJ. Use of complementary therapies among primary care clinic patients with arthritis. Prev Chronic Dis. 2004;1(4):A12.

48. Patterson $\mathrm{C}$, Arthur H. A complementary alternative medicine questionnaire for young adults. Integr Med Insights. 2009;4:1-11.

49. Kaboli PJ, Doebbeling BN, Saag KG, Rosenthal GE. Use of complementary and alternative medicine by older patients with arthritis: a population-based study. Arthr Rheum. 2001;45(4):398-403.

50. Quandt SA, Chen H, Gryzywacz JG, Bell RA, Lang W, Arcury TA. Use of complementary and alternative medicine by persons with arthritis: results of the National Health Interview Survey. Arthr Rheum. 2005;53(5):748-55.

51. Sleath B, Callahan L, DeVellis RF, Sloane PD. Patients' perceptions of primary care physicians' participatory decision-making style and communication about complementary and alternative medicine for arthritis. J Complement Alt Med. 2005;11(3):449-53.

52. Saydah SH, Eberhardt MS. Use of complementary and alternative medicine among adults with chronic disease: United States, 2002. J Complement Alt Med. 2006;12(8):805-12.

53. Rao JK, Mihaliak K, Kroenke K, Bradley J, Tierney WM, Weinberger M. Use of complementary therapies for arthritis among patients of rheumatologists. Ann Intern Med. 1999;131(6):409-16.

54. Fisher P, Ward A. Complementary medicine in Europe. BMJ. 1994;309:107-11.

55. Wang B-R, Choi IY, Kim K-J, Kwon YD. Use of traditional Korean medicine by patients with musculoskeletal disorders. PLoS One. 2013;8(5), e63209. doi:10.1371/journal.pone.0063209.

56. Callahan LF, Wiley-Exley EK, Mielenz TJ, et al. Use of complementary and alternative medicine among patients with arthritis. Prev Chronic Dis. 2009;6:44.

57. World Health Organization. WHO Traditional Medicine Strategy2002-2005. Geneva: WHO Health Organization; 2002.http://www.wpro.who.int/health_technology/book_who_traditional_medicine_strategy_2002_2005.pdf. Html. Accessed 12/03/2015.

58. Wolsko PM, Eisenberg DM, Davis RB, Kessler R, Phillips RS. Patterns and perceptions of care for treatment of back and neck pain. Results of a national survey. Spine. 2003;28(3):292-8.

59. Perry R, Dowrick CF. Complementary medicine and the general practice: an urban perspective. Complement Ther Med. 2000;8:71-5.

60. Lewith GT, Hayland M, Gray SF. Attitudes to and use of complementary medicine among physicians in the United Kingdom. Complement Ther Med. 2001;9:167-72.

61. Čižmešija T, Bergman-Markovac B. Use of complementary and alternative medicine among patients in primary health care. Acta Med Croatica. 2008;62:15-22

62. Palinkas LA, Kabongo ML, The SURF*NET study group. The use of complementary and alternative medicine by primary care patients. J Fam Pract. 2000;49(12):1121-113.

63. Mollaoğlu M, Aciyurt A. Use of complementary and alternative medicine among patients with chronic diseases. Acta Clin Croat. 2013;52:181-8.

64. Cuellar N, Butts JB. Caregiver distress: what nurses in rural settings can do to help. Nurs Forum. 1999;34:24-30.

65. Bernard SL, Jordan JM, Cook HL. Gender and ethnic differences in alternative and conventional arthritis remedy use among community-dwelling rural adults with arthritis. Arthritis Care Res. 1996;9:384-90.

66. Bukovčan T. I want to choose whom I love and where to I go for treatmentactivism in researching CAM in Croatia. Ethnological Res. 2008;77-85.

67. Barry PJ, Kemper KJ. Alternative medicine use by homeless youth. Achieves Paediatric Adolescent Med. 1998;152(11):1071-5.

68. Billot L, Mouchtouris A, Deschamps JP, Romero Ml, Zubarew T. French adolescent attitudes towards informal care for physical and emotional or relational problems. Acta Paediatr. 2002;9(4):466-74.

69. Arthur H, Noesgaard C. Exploring adolescent complementary/alternative medicine (CAM) use in Canada. J Interprof Care. 2007;22(1):45-55. 